\title{
Prehistoric Decline of Genetic Diversity in the Nene
}

\author{
Ellen E. Paxinos, ${ }^{1 *}$ Helen F. James, ${ }^{2}$ Storrs L. Olson, ${ }^{2}$ \\ Jonathan D. Ballou, ${ }^{1}$ Jennifer A. Leonard, ${ }^{3}$ Robert C. Fleischer ${ }^{1,2} \uparrow$
}

The nene (or Hawaiian goose, Branta sandvicensis) once occurred on most of the main Hawaiian Islands (1), but by Captain Cook's arrival in 1778, nene were found only on the island of Hawaii (2). A decline that began in the 1800 s reduced the nene population to fewer than 30 individuals by the middle of the 20th century (2). Nene currently have extremely low levels of genetic variation (3). We questioned whether this low genetic variation resulted from the recent population decline or was a natural consequence of living on islands (theory and empirical evidence indicate that island taxa should and do have lower genetic variability than mainland ones) (4). Here we report an assessment of genetic variation in samples of nene on the island of Hawaii from four time periods (Fig. 1): 26 extant captive and wild birds, 14 historical museum specimens (collected between 1833 and 1928), 16 bones from archaeological middens [radiocarbon dated at 160 to 500 radiocarbon years before present (rybp)], and 14 bones from paleontological sites (500 to 2540 rybp).

We analyzed DNA sequence variation in the mitochondrial control region (CR), following very strict methodologies to avoid and detect contamination in ancient samples (5). We found no variation across 847 nucleotide sites among extant nene (haplotype diversity, $\mathrm{H}=0$ ) and designate this sequence as haplotype RH. For the ancient samples, we obtained sequences of 217 sites from the highly variable left domain of the CR and 92 sites from the less variable right domain (6). Unexpectedly, only one museum specimen sequence differed from the RH haplotype (E1, Fig. 1B), and all archaeological bones (sampled from eight different caves) possessed RH. Only the paleontological nene exhibited levels of CR variation typical of geese (5): six individuals had $\mathrm{RH}$ and eight had one of six additional haplotypes (Fig. 1B). $\mathrm{H}$ was 0.802 (multinomial lower $95 \%$ $\mathrm{CI}=0.67)$ in the paleontological sample, but only 0.067 (upper $95 \% \mathrm{CI}=0.26$ ) in the archaeological and museum specimen samples combined (6).

Thus, our results indicate that the nene populations on Hawaii lost most of their mitochondrial DNA (mtDNA) variability long before their historic population decline. Monte Carlo simulations run for 150 generations (about 600 years) suggest that the most likely explanation is a prehistoric population bottleneck (6). A reduction of $\mathrm{H}$ from 0.80 to 0.26 in populations of varying size (500 to 10,000$)$ can only occur if the populations decline to fewer than 270 females (for a rate of decline of $r=-0.01$ ) or to fewer than 20 females (for $r=-0.05$ ). In addition, in the absence of population decline, an improbably large selection coefficient of 0.10 would be required to change $\mathrm{RH}$ frequen- cy from 0.43 to 0.97 over 150 generations. Our radiocar-

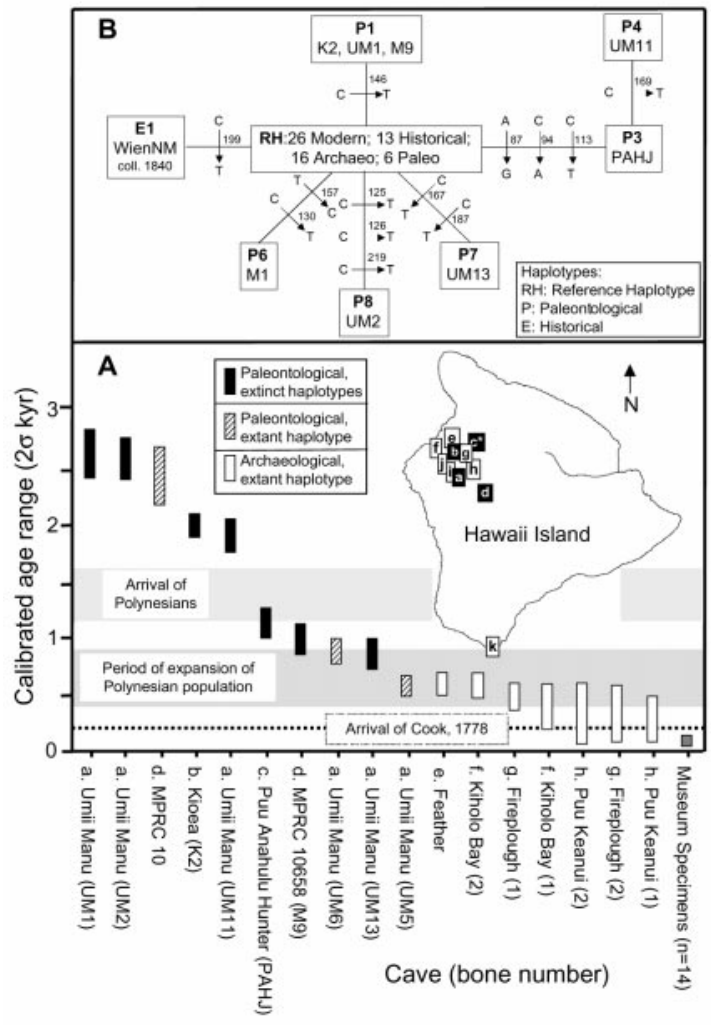

Fig. 1. (A) ${ }^{14} \mathrm{C}$ age ranges of 17 nene bones from Hawaii Island with extinct versus extant haplotypes. Ranges are estimates of calendar year ages (with $95 \%$ probability), calculated from dates provided by the Rafter Radiocarbon Laboratory, New Zealand, and Instaar Laboratory, Boulder, Colorado, with CALIB 4.1. Time frame of Polynesian colonization and population growth summarized from (7). (Inset) Map of Hawaii Island with positions of cave collecting sites (archaeological: open symbols; paleontological: filled symbols). Letters correspond to localities listed on the axis, plus three sites from which undated bones were recovered: Delissea (i), Pu'u Wa'awa'a (j), and Hali'i (k). (B) Network of haplotypes identified in nene mtDNA CR sequences. Arrows denote nucleotide substitutions. Numbers adjacent to arrows indicate the number of the base from position 78 of the Gallus sequence (NC001323). Genbank accession numbers for CR sequences are AY099099 to AY099106. bon chronology (Fig. 1A) suggests that the nene's loss of genetic variability took place during a period of prehistoric human population growth (900 to 350 years ago), when settlements expanded into marginal ecological zones (7). Radiocarbon dates $(1,5,8)$ indicate that the extirpation of the nene on Kauai and the extinction of at least five of the nine large ground-dwelling Hawaiian birds (1) occurred during this time period. Ecological changes associated with human settlement are assumed to have caused the extinctions (1) and apparently caused a dramatic reduction in genetic diversity in the nene on Hawaii as well.

Ultimately, we must ask why the nene population on Hawaii could escape prehistoric extinction while many other Hawaiian birds did not. Cultural changes may have created better conditions for nene, such as more open habitat, while at the same time warfare may have created noman's-lands safer for wildlife. Prohibitions by ruling elites (kapu) may have protected the birds, and it is possible that they were even brought under domestication or semidomestication. Paleontological studies have shown how broadly devastating the impact of prehistoric humans was on insular organisms, as most vividly shown by the total extinction of hundreds of species (1). Our findings demonstrate that these prehistoric influences may still be reflected in the genetic makeup of insular species that survived until the present, many of which, like the nene, are endangered. In addition, we have confirmed that at least one islanddwelling species, the nene, did not always have the low genetic variability predicted by its history as an island taxon (4).

\section{References and Notes}

1. S. L. Olson, H. F. James, Ornith. Monogr. 45, 1 (1991).

2. J. Kear, A. J. Berger, The Hawaiian Goose: An Experiment in Conservation (Buteo Books, Vermillion, SD, 1980).

3. E. H. Rave, R. C. Fleischer, F. Duvall, J. M. Black, Conserv. Biol. 8, 744 (1994).

4. R. Frankham, Heredity 78, 311 (1997).

5. E. E. Paxinos et al., Proc. Natl. Acad. Sci. U.S.A. 99, 1399 (2002).

6. Additional methods and acknowledgments are available on Science Online.

7. P. V. Kirch, Feathered Gods and Fishhooks: An Introduction to Hawaiian Archaeology and Prehistory (Univ. of Hawaii Press, Honolulu, HI, 1985).

8. H. F. James et al., unpublished data.

\section{Supporting Online Material}

www.sciencemag.org/cgi/content/full/296/5574/ 1827/DC1

Methods

Acknowledgments

${ }^{1}$ Conservation and Research Center, Smithsonian Institution, 3001 Connecticut Avenue, NW, Washington, DC 20008-0551, USA. ${ }^{2}$ Department of Systematic Biology, National Museum of Natural History, Smithsonian Institution, Washington, DC 20560, USA. ${ }^{3}$ Department of Organismal Biology, Ecology, and Evolution, University of California, Los Angeles, CA 90095-1606, USA.

*Present address: Virologic, Inc., 345 Oyster Point Boulevard, So. San Francisco, CA 94080, USA.

$\dagger$ To whom correspondence should be addressed. E-mail: fleischer.robert@nmnh.si.edu 